\title{
Metal-loaded polystyrene-based activated carbons as DBT removal media via reactive adsorption
}

\author{
CO Ania ${ }^{\S}$ TJ Bandosz*
}

Department of Chemistry, The City College of the City University of New York, 138th Street at Convent Avenue, New York, NY 10031

$\S$ Present address: CRMD, CNRS-University, $1 b$ Rue de la Férollerie, 45071 Orléans Cedex 02, France

\begin{abstract}
To improve the desulfurization capability of activated carbons, new metal-loaded carbonbased sorbents containing sodium, cobalt, copper, and silver highly dispersed within the carbon matrix were prepared and tested at room temperature for DBT adsorption. The content of metals can be controlled by selective washing. The new adsorbents showed good adsorption capacities and selectivity towards DBT. The metals incorporated to the surface act not only as active sites for selective adsorption of sulfur-containing aromatic compounds, but also as structural stabilizers of the carbon materials, and as catalyst initiators in reactive adsorption. Depending on the reactivity of the metal used, the adsorption capacity of the activated carbons significantly varied. Cobalt and copper loaded carbons showed the highest uptakes, due to not-well defined catalytic synergetic effects. Besides, the presence of sulfur compounds in the structure of the carbon as a result of the sulfonic moiety of the precursor, results in sulfur- sulfur specific interactions leading to an enhancement in the adsorption capacity for DBT removal.
\end{abstract}

Keywords: chemically modified carbons, impregnation, adsorption properties 


\section{INTRODUCTION}

Worldwide, efforts have begun to systematically reduce the sulfur level in transportation fuels in anticipation to the upcoming environmental regulations that will be implemented in industrialized countries [1-4]. These requirements to produce low-sulfur fuels impose significant efforts in current desulfurization methods and in the development of new technologies. In this regard, it is easy to understand that finding an economical way to selectively remove sulfur from gasoline and diesel fuel has become a crucial for refineries to keep them from going out of business, as the challenge also settles in developing and/or improving technologies that do not substantially increase the cost of fuels.

The conventional approach for deep desulfurization of fuel feedstocks in petroleum refining is based on a catalytic process, called hydrodesulfurization (HDS) [5, 6]. To comply with the new regulations, this approach faces an important challenge: the removal of polyaromatic sulfur-containing compounds without an unavoidable and significant capital investment, thereby drastically increasing the costs of fuels [7]. One way to avoid the increased costs is to use different approaches, such as adsorption which operates at ambient temperature and pressure. Having the advantages of being a low-energy demanding process, availability of regeneration of the spent adsorbent, broad availability of adsorbents, this approach is an attractive field of research [8-13]. Extensive research has been done to find adsorbent materials that are highly selective toward sulfur compounds, in the presence of the coexisting aromatic hydrocarbons and olefins that account for a large excess in the fuel. Recently, it has been shown that an introduction of certain metals to the surface of a carbonaceous support can significantly increase the dibenzothiophene (DBT) 
removal capacity [14]. The adsorbents reported were highly selective toward aromatic sulfur compounds which are not efficiently removed by HDS.

In recent research performed in our laboratory, several commercial carbon materials were tested as adsorbents of DBT from liquid phase. Based on the results, $[15,16]$ it was found that the surface chemistry of the carbon plays an important role in the DBT adsorption. Strong oxidation of the carbon materials lead to an enhancement in DBT removal, whereas unexpectedly high adsorptive capacities were obtained on a polystyrene-based saltsderived carbon containing large amounts of sulfur within the carbon matrix.

The objective of this research is to explore the performance of carbon adsorbents modified with metals as media for DBT removal. The aim is to enhance the adsorption forces and selectivity and/or to induce reactive adsorption via incorporation of metallic species to the carbon matrix. Hence, the mechanism of desulfurization via reactive adsorption on carbon materials was investigated. The previous studies on carbonization of transition metal-based polymeric salts of polystyrene sulfonic acid co-maleic acid showed that using this precursor, highly porous materials can be obtained and the content of metals can be controlled by selective washing [15-17]. In this regard, metals of different reactivity, such as sodium, cobalt, copper and silver were incorporated and co-pyrolyzed with a polymeric organic salt, and the performance for DBT adsorption of the resulting carbon adsorbents was studied. The effect of reactivity of the metal used, due to catalytic synergetic effects was investigated, and the performance of these materials was compared to that attained with other adsorbents addressed in the literature.

\section{EXPERIMENTAL}




\subsection{Materials}

The procedure for the preparation of the metal-loaded carbons with high surface areas and well-developed microporosity from organic salts containing metallic cations has been described elsewhere [17]. Briefly, the organic polymer/carbon precursor (polystyrene sulfonic acid co-maleic acid sodium salts was ion-exchanged with nitrates of the corresponding metals (i.e., copper, cobalt, and silver) for 24 hours, and then carbonized in nitrogen at $800^{\circ} \mathrm{C}$. The sodium form of the carbon material was obtained by direct carbonization of the commercial polymer. The excess of water-soluble inorganic salts (sodium and excess of the transition metal salts) was removed by washing with distilled water, until constant $\mathrm{pH}$ of a leachate. The carbons were then dried and the tests for adsorption from liquid phase were carried out. The samples are referred to in text as PS-M, where $\mathrm{M}$ denotes the metal ion. The copper-loaded samples were gradually washed with 12 $\% \mathrm{HCl}$ to decrease the metal content on the surface. On a first step the samples were washed for 24 hours, and later an extensive washing was performed for 3 weeks, until no copper traces were observed in the leachate. The samples are referred to as PS-Cu W and Ps-Cu WW, respectively. Then the Soxhlet washing was done with distilled water to remove the excess of water-soluble chlorides and hydrochloric acid. A scanning electron microscope (SEM, Zeiss, DSM 942) was used to obtain qualitative information on the morphological appearance and distribution of the metals on the carbon surface.

\subsection{Adsorption from solution}

Adsorption of DBT was carried out at room temperature in a stirred batch system. Before these experiments, the kinetic studies were performed to determine the equilibration time of the system. Different amounts of carbons (from $25 \mathrm{mg}$ to $1 \mathrm{~g}$ ) were weighed and added 
to 15 bottles containing $40 \mathrm{ml}$ of the sulfur-containing solution with an initial concentration of 1000 ppmw of DBT (ca. $178 \mathrm{ppmw}$ of S). The BDT solutions were prepared in hexane. The covered bottles were placed in a shaking bath and allowed to shake for $72 \mathrm{~h}$ at a constant temperature. After equilibration the concentration in the solution was determined using a UV spectrophotometer at the corresponding wavelength. The amount adsorbed was calculated from the formula $\mathrm{q}_{\mathrm{e}}=\mathrm{V}\left(\mathrm{C}_{0}-\mathrm{C}_{\mathrm{e}}\right) / \mathrm{m}$, where $\mathrm{q}_{\mathrm{e}}$ is the amount adsorbed, $\mathrm{V}$ is the volume of the liquid phase, $\mathrm{C}_{\mathrm{o}}$ is the concentration of solute in the bulk phase before it comes in contact with the adsorbent, $\mathrm{C}_{\mathrm{e}}$ is the concentration of the solute in the bulk phase at equilibrium, and $\mathrm{m}$ is the amount of the adsorbent. For selectivity studies, a mixture of $0.1 \mathrm{wt} \%$ of DBT -corresponding to $178 \mathrm{ppmw}$ of S- and $0.12 \%$ naphthalene was used. The changes in the concentration of DBT and naphthalene were followed using UV spectroscopy.

The equilibrium data was fitted to the so-called Langmuir-Freundlich single solute isotherm [18], which has the equation:

$$
q_{e} / q_{o}=\frac{(K C)^{n}}{1+(K C)^{n}}
$$

where $q_{e}$ is the adsorbed amount of the solute per unit gram of adsorbent, $q_{o}$ is its maximum adsorption per unit weight of the adsorbent, $K$ is the Langmuir-type constant defined by the Van't Hoff equation, and the exponential term $n$ represents the heterogeneity of the site energies. The fitting range was from 0 to $250 \mathrm{mg}$ of $\mathrm{S}$ per gram of activated carbon (recalculated from its content in DBT).

\subsection{Textural and chemical characterization}

Textural characterization was carried out by measuring the $\mathrm{N}_{2}$ adsorption isotherms at $77 \mathrm{~K}$. Before the experiments, the samples were outgassed under vacuum at $393 \mathrm{~K}$. The 
isotherms were used to calculate the specific surface area, $\mathrm{S}_{\mathrm{BET}}$, total pore volume, $\mathrm{V}_{\mathrm{T}}$, and pore size distributions. The pore size distributions were evaluated using density functional theory (DFT) [19].

\subsection{Thermal analysis}

Thermal analysis was carried out using a TA Instrument thermal analyzer. The instrument settings were heating rate $10 \mathrm{~K} / \mathrm{min}$ and nitrogen atmosphere with $100 \mathrm{ml} / \mathrm{min}$ flow rate. For each measurement about 25 mg of a ground carbon sample was used.

\subsection{XRF of the carbons}

X-Ray Fluorescence analysis was applied to study the content of sulfur and copper in the carbons. For this purpose, SPECTRO Model 300T Benchtop Multi-Channel Analyzer from ASOMA Instruments, Inc. was used. It contains a titanium (Ti) target X-ray tube with Mo2mil filter and high resolution detector with a filter. A home developed methods were selected to identify the sulfur and acquisition conditions were the following: voltage 9.0 $\mathrm{kV}$, current $280 \mu \mathrm{A}$, count time $100 \mathrm{sec}$, warm-up 3 min. Instrument reference temperature was $293 \mathrm{~K}$ and background conditions: lower ROI 3200, upper ROI $5750 \mathrm{keV}$. The amount of sulfur and copper were determined based on calibration curves prepared from a carbonaceous matrix.

\subsection{SEM}

The morphology of the carbon materials was characterized using a Ziess DSM 942 scanning electron microscope. The carbon particles were dispersed on a graphite adhesive tab placed on an aluminum stub. The images were generated in the backscattered electron 
signal mode, which yielded better quality pictures. In some cases, where a higher resolution was required, the settings were changed to the secondary electron mode.

\section{RESULTS AND DISCUSSION}

Figure 1 illustrates the DBT adsorption isotherms on the metal-loaded carbons. All of them belong to the L type in the Giles classification [20]. The shape of the isotherm provides qualitative information on the nature of the solute-surface interaction. In all cases a concavity towards the abscissa axis is displayed. This indicates that as more sites in the substrate are filled, it becomes increasingly difficult for a fresh solute molecule to find a vacant site. This shape of isotherm is also characteristic of systems with no strong competition of the solvent for the active sites of adsorption. The adsorption isotherms show a tendency to reach a plateau at high equilibrium concentration of DBT (i.e., low dose of adsorbent). Since the amount adsorbed steadily increases, the saturation limit at low doses of adsorbent is not attained.

The adsorptive capacity of the carbons was obtained by fitting the experimental data to the Langmuir-Freundlich equation [18]. The results are shown in Table 1, along with the LF parameters of surface heterogeneity and the linear range and the correlation coefficients. The adsorptive capacity of a microporous commercial carbon (BP from Calgon) is also

shown for comparison. The excellent goodness of the fit (in all cases $\mathrm{R}^{2}>0.99$ ) indicates that the LF equation is suitable for application for the systems studied.

The results obtained for adsorption of DBT show that the studied carbons have favorable features for the removal of DBT. The adsorption capacities are comparable to and/or larger 
than those reported in the literature for activated carbons and zeolites [13, 21-25]. The good performance of our carbons in the process of DBT removal can be linked to their high content of sulfur (Table 2). It is likely that disulfur quazibridges are formed between the sulfur atom of DBT and the sulfur species present on the initial carbon surface. These bonds are expected based on the high polarizability of the sulfur atom.

Moreover, metallic species formed during carbonization of the corresponding exchanged polymer, are also responsible for the good adsorptive performance (Table 2). The best performance is obtained for the samples loaded with cobalt and copper, and the worst for the carbon-derived from the polymer in the initial sodium form. The effect of transition metals on specific DBT adsorption is also corroborated by the low values of the exponent $n$ of the LF equation, which indicates the presence of sites with different energies toward DBT adsorption than those in the case of PS-Na carbon [26]. To investigate the role of the metal species in the enhanced DBT adsorption, the structural and chemical characteristics of the carbons have to be addressed. The nature of the metallic centers, the content of the metals, as well as the porosity of the adsorbents were evaluated.

The measurement of the $\mathrm{pH}$ of the carbons in a water suspension, revealed rather acidic character of the studied carbons (Table 2). These acidic values are the result of the presence of acidic oxygen containing groups (i.e., carboxylic). When the materials were exposed to air (oxygen) after carbonization, a very strong exothermic reaction was noticed, which leads to formation of functional groups at the edges of carbon crystallites. The $\mathrm{pH}$ values of samples loaded with transition metals are slightly higher that that for the samples derived from the sodium form. This is the result of the presence of inorganic species in the materials (i.e, in the form of oxides/sulfides coming from the decomposition of nitrates, carbonates and sulfates from the moiety of the carbon precursor) which are not removed by water washing. 
The DTG curves (Figure 2) for the samples after carbonization and washing (for PS-Cu series) confirmed the presence of the acidic groups, and the differences in the species present on the materials surface. While the first peak at temperatures lower than $100^{\circ} \mathrm{C}$ is attributed to the removal of physisorbed water, a common feature in all cases is a broad peak between $200-400^{\circ} \mathrm{C}$, representing the decomposition of the carboxylic groups into water and $\mathrm{CO}_{2}$, as indicated elsewhere [27]. The peaks at higher temperatures observed for the cobalt-loaded carbon represent the reduction of metal sulfates and/or sulfides. In PS-Ag sample, the decomposition of silver oxides likely present on the surface occurs at around $300^{\circ} \mathrm{C}$, overlapping the decomposition of acidic groups. It is interesting that for the copperloaded material, the intensity of the peak at $200-400^{\circ} \mathrm{C}$, largely exceeds that for the other materials. This peak might be attributed to the decomposition of copper carbonates formed during carbonization (from the moiety of the carbon precursor) and overlaps with those from decomposition of oxygen-containing groups.

Washing copper containing samples with $\mathrm{HCl}$ (sample $\mathrm{PS}-\mathrm{Cu} \mathrm{W}$ ) confirms the above mentioned hypothesis. During this process, hydrogen sulfide rotten egg odor was detected, indicating the reaction of $\mathrm{HCl}$ with sulfides. The peaks over $600^{\circ} \mathrm{C}$ initially present on the DTG profiles disappear after acid washing, owing to the dissolution of copper sulfates. The peak at $200-400^{\circ} \mathrm{C}$, although with smaller intensity still appears after acid treatment despite the blue color of the leachate after washing with $\mathrm{HCl}$.

Support for the results described above are changes in the content of copper present in the sample before and after acid washing. They are summarized in Table 2. After washing with $\mathrm{HCl}$ the copper content in PS-Cu W decreased only about 30\%, suggesting that copper 
species are not easily removed using this kind of treatment. Further washing with $\mathrm{HCl}$ (for about 3 weeks) and water resulted in much lower copper content in the sample -PS-Cu WW-. Those changes in metal content have also an effect on the porosity of the carbon. This issue is addressed below.

The changes in the morphology of the metal-containing carbons seen on SEM micrographs (Figure 3) are also consistent with the above discussion. On the surface of samples obtained from copper and silver salts numerous particle aggregates of metal of a few nm in size are revealed (Figure 3). These clusters appear randomly dispersed on the surface of the carbon matrix. This effect was not observed in the case of cobalt-loaded sample, indicating that this metal is much better dispersed in the carbon matrix. Moreover, EDX analysis showed that despite the clustering, some copper is also present within the carbon matrix (Figure 4). The diffraction patterns for the cobalt-loaded sample showed the presence of metal sulfides, sulfur, and oxides agglomerates. Similar results were obtained by Hines et al. when the same polymeric salts were used as carbon precursors [17].

The chemical status of the copper or silver in those clusters still remains under investigation. Taking into account the low reduction potential of the pair $\mathrm{Cu}(\mathrm{II}) / \mathrm{Cu}(+0.34$ $\mathrm{V}$ ), and the reductive atmosphere during carbonization, the copper in these aggregates is assigned to copper zero and/or copper (II). It seems reasonable to assume that after ionexchange of the carbon precursor, the metals are highly dispersed within the carbonaceous matrix, as the precursor is a polymer with numerous functional moieties that allows metal bonding and chelating. During carbonization formation of metallic particles occurs via migration of the reduced metals to the surface [17, 28-31]. 
Detailed characteristics of the pore structure of the activated carbons obtained by pyrolysis of the polystyrene-organic salts are presented in Table 3. The nitrogen adsorption isotherms for the adsorbents investigated are presented in Figure 5. Analysis of the data indicates variations in the porosity of the carbons obtained caused by the differences in metal cation chemistries occurring during carbonization. More elaborated discussion on porosity developed and the role of the metal on the pyrolysis is included in our previous work [17].

Carbonization of transition metal-based salts of polystyrene sulfonic acid co-maleic acid results in formation of porous materials. Only copper and silvers salts based carbons significantly differ from others in the textural features. All the samples exhibit nitrogen adsorption isotherms of type I of the BDDT classification [32]. Although all materials have a predominantly microporous structure, the isotherm for PS and PS-Co have hysteresis loops, which is indicative of the development of mesopores of specific shape. In the case of PS-Co, the hysteresis loop appears at rather low relative pressures, pointing out a shift of mesopore size to higher values.

Analysis of the structural parameters calculated from the nitrogen adsorption isotherms indicates that adsorbents obtained from sodium and cobalt salts have larger surface areas and higher volumes of micropores than those for the PS-Cu and PS-Ag. The degree of microporosity (ratio of $\mathrm{V}_{\text {mic }} / \mathrm{V}_{\mathrm{t}}$ ) is around $45 \%$ for sodium and cobalt-containing samples, as opposed to 39\% for copper and silver ones. PS-Na sample is the most microporous one, with a high contribution of micropores smaller than $0.7 \mathrm{~nm}$ and mesopores. The low porosity of PS-Cu and PS-Ag is undoubtedly related to the low standard reduction potential of those metals, in comparison with that of cobalt. Hence, owing to the reductive 
atmosphere of carbonization, copper and silver are likely reduced and migrate to the surface, either inhibiting the formation of a large porous structure or blocking the porosity of the resulting carbon. However, this issue was not further investigated as the role of copper in the development of porosity was out of the scope of this work.

Acid washing affected the porosity of the copper-modified carbons. After this treatment a remarkable increase in surface area and pore volume is noticed (Figure 5). The corresponding increase in the BET surface area for PS-Cu W is about $32 \%$. The analysis of the PSD for this sample indicates similarity in pore sizes between PS-CuW and PS-Cu carbon (Figure 6) but the former sample has much higher pore volumes. This indicates that in the case of PS-Cu there is no partial constriction at the entrances of the pores, but their complete blockage resulting in their inaccessibility to nitrogen molecules. Extensive washing resulted in an increase in the volume of narrow micropores of PS-Cu WW in comparison to that for Ps-Cu W. This supports our finding about the presence of dispersed metallic species in the small pores. A similar behavior was observed for cobalt-modified samples in previous studies [17]. As mentioned above after acid washing the porous features of Ps-Cu WW are still less developed than those of PS-Co or Ps-Na.

From all three metals, the material obtained from the sodium form of the polymer looks as the least active in the process of enhancement of DBT removal at room temperature whereas cobalt-based adsorbent has a superior performance. In the case of samples PS-Na and PS-Co their good performance of DBT reactive adsorption might be explained by two factors: their high pore volume and sulfur content [15]. In spite of the limited structural parameters of copper-loaded samples, these adsorbents showed extremely large capacities for DBT adsorption, close to that obtained for PS-Co sample with a much larger porosity. 
To understand the role of the metal species, the content of copper in samples is compared to the amount of DBT adsorbed (Table 4). It is interesting that the efficiency of copper centers (ratio of number of moles of DBT adsorbed to the number of metal ions) is constant for the samples with high metal content (PS-Cu and PS-CuW) in spite of the fact that the content of this metal is 1.5 times lower after the first washing step (PS-Cu vs PS$\mathrm{Cu} \mathrm{W}$ ). Although not all copper is active (only about $50 \%$ of atoms), the efficiency of the centers remain similar even after large portion of the surface area became available for the adsorbate molecule. Since micropores of activated carbons are active centers in DBT adsorption [15], it seems reasonable that the only active copper that contributes to DBT adsorption is that present in the micropores. Indeed, acid washing should result mainly in the removal of the most external copper agglomerates, while in the species present in the micropores are expected to be removed less efficiently. Moreover, another factor contributing to the relatively high amount of DBT adsorbed in spite of a decrease in the content of copper is the effect of "cleaning" the surface of the carbon and opening of new micropores. When very small amount of metal is present adsorption decreases. However, in this case the effect of the carbon surface (i.e., porosity and acidic functionalities) is more pronounced and it cannot be clearly separated from the effects of metals. Thus despite the low efficiency of metal centers, the amount adsorbed is considerably large. Support for this is the changes in the PSDs for the samples after adsorption (Figure 6). In the case of Ps-Cu and the cobalt and silver-containing samples, the main difference caused by DBT adsorption is a decrease in the volumes of pore narrower than $1 \mathrm{~nm}$. The lack of changes in the range of mesopores suggests that reactive adsorption only takes place in the microporosity of the samples. 
To investigate the role of metals on the process of DBT adsorption, DTG curves of the carbons after DBT exposure were analyzed (Figure 7). The graphs have been normalized by subtraction of the corresponding profiles of the raw carbons, to avoid a misinterpretation of the peaks linked to the decomposition of the surface functionalities. In all cases two peaks with different widths and intensities are observed. The first peak centered at temperature lower than $400^{\circ} \mathrm{C}$ is assigned to hexane and DBT physisorbed in the porous structure of the carbons [15]. The second peak corresponds to specific interactions between the DBT molecule with the active sites of the carbon surface. It is interesting that this peak appears at the same temperature for all samples, regardless the type or amount of metal incorporated on the surface, suggesting that the same forces of adsorption are involved. These specific interactions are likely sulfur-oxygen and/or disulfur quazibridges formed between the sulfur atom of DBT and the sulfur species present on the carbon surface.

Calculation of the weight loss from the desorption profiles for the samples after DBT adsorption, after its correction for the weight loss of the initial materials, indicates that the mass loss ranges from $6.6 \%$ for PS-Cu to almost $9 \%$ in the case of PS- Na carbon. Although the mass loss hereby calculated also includes certain amount of the solvent physisorbed in the carbon, even if we assume that all the losses correspond to DBT, still the weight loss of the samples after adsorption does not account for the total amount of DBT adsorbed (Table 5). This shows that large amounts of sulfur remain in the carbon matrix and it is not removed upon heating. If all DBT was physisorbed in the micropores due to dispersive interactions, we would expect reversible bonds and thus the mass loss would perfectly match the amount of DBT adsorbed. Thus, based on our results there must be a contribution of irreversible or quasi-irreversible adsorption, linked to the presence of the metal species. 
DTG profiles of the samples with different copper contents revealed that the decrease in the amount of metallic active center is accompanied by changes in the intensities of the desorption peaks at both temperatures. The decrease in the intensity of the peak at high temperatures indicates that these adsorption forces are linked to either the content of active copper species, or sulfur and oxygen-containing functionalities, which are largely removed by acid washing. In contrast, the intensity of the low temperature peak increases, which is reasonable as this peak was assigned to DBT physisorbed on porous structure. The mass loss evaluated from TA is higher for the samples with the low copper content, indicating a relationship between the metal active centers and the irreversible adsorption.

A specific role of the metals for DBT adsorption lies in being high-energy centers for specific DBT removal via strong interactions with sulfur in the confined pore space. These forces likely cause carbon sulfur bond to break resulting in sulfide formation owing to a strong affinity of sulfur to transition metals. As mentioned above, in the case of Ps-Na and PS-Co, besides their porosity, the high sulfur content and presence of acidic groups might be responsible for the large uptake on these carbon. For silver-loaded carbon, the enhancement in the uptake of DBT is attributed to the $\pi$-complexation and silver-sulfur bonds promoted on the carbon surface. This phenomenon was extensively studied by Yang et al. [23, 25].

For the copper-loaded carbon, the situation seems to be more complex. $\pi$-complexation is not expected to take place, as the active species is not $\mathrm{Cu}(\mathrm{I})$. During carbonization of the carbon precursor a reactive atmosphere is generated, thus the copper is mainly in the forms of either zero valence metal clusters, or in an upper oxidation state. A good performance in 
the process of DBT removal may be associated with reactive adsorption which may occur via breaking of the sulfur-carbon bond in the thiophenic compound by oxygen, assuming that copper acts as oxygen activator [33, 34]. The activation of oxygen by copper has already been reported in the literature in modified cerium oxide systems for sulfidation [35] and as promoter of $\mathrm{H}_{2} \mathrm{~S}$ oxidation in carbon containing binder as adsorbents of hydrogen sulfide [36].

To investigate if the nature of the metal specific interactions with DBT molecule is selective, adsorption of DBT was also performed in the presence of naphthalene (a hydrocarbon usually present in high concentrations in hydrocarbon solutions) on copper salts derived samples. The results of the uptake of DBT in the presence of naphthalene are shown in Table 6. As expected, naphthalene is also retained on the activated carbons (physisorbed), since the molecular structure is similar to DBT and non specific interactions take place on the non-polar basal planes of the adsorbent. Nevertheless, an important finding is in the fact that for high concentration of copper active centers, the amount of naphthalene adsorbed decreased significantly. This corroborates the hypothesis of selective interactions occurring between the copper and sulfur atoms of DBT. When adsorption experiments were performed for naphthalene in the absence of DBT, the amount adsorbed in all cases was higher than that when DBT was present (Table 6). Although this indicates that there is a competition of both molecules for the actives sites of the carbon surface, DBT seems to be able to displace naphthalene.

Since the main requirement of reactive adsorption is a high selectivity towards sulfurcontaining organic compounds, the active centers of the adsorbents should be tailored minimizing the affinity towards naphthalene-like compounds. Metal-loaded carbon hereby 
described showed a large contribution of specific and selective interactions towards DBT. Combining these advanced adsorbents with new types of active catalytic species, can result in extremely high desulfurization performance. The application of metal-loaded carbons for a second-stage deep desulfurization process can be a very promising alternative to comply with current legislation.

\section{CONCLUSIONS}

The results described in this paper present the superior DBT removal capacity of metalloaded polystyrene-based adsorbents to that attained with non-modified commercial activated carbons. From all the metals, cobalt and copper seem to be the most efficient. Moreover, the presence of high sulfur contents and acid groups on the carbon surface contribute to the enhancement of the adsorption capacity. The copper containing adsorbents, despite the smallest surface area and pore volumes, show an extremely large capacity for DBT removal. Although the mechanism of enhancement is not yet well understood, it is likely that copper acts as an oxygen activator, enabling cleavage of sulfurcarbon bonds in the thiophenic compound. The presence of copper species also increases the selectivity of the DBT adsorption when a large amount of a non-sulfur containing aromatic hydrocarbon of similar structure to that of DBT is present.

\section{ACKNOWLEDGEMENTS}

The authors wish to thank FICYT and PSC CUNY for financial support. We thank Dr. Parra for kindly providing SEM and XRD. 


\section{REFERENCES}

[1] EPA-Gasoline RIA, Regulatory Impact Analysis-Control of Air Pollution from New Motor Vehicles: Tier 2 Motor Vehicle Emissions Standards and Gasoline Sulfur Control Requirements, US Environmental Protection Agency, Air and Radiation, EPA420-R-99-023, December 1999

[2] US EPA, Control of Air Pollution from New Motor Vehicles; Amendment to the Tier2/Gasoline Sulfur Regulations, EPA 40 CFR Parts 80 and 86, April 2001

[3] Directive 1998/70/EC of the European Parliament and of the Council of 13 October 1998, relating to the quality of petrol and diesel fuels and amending Council Directive 93/12/EEC. Journal L 350, 28/12/98, P. 005-0068

[4] Directive 2003/17/EC of the European Parliament and of the Council of 3 March 2003 amending Directive 98/70/EC relating to the quality of petrol and diesel fuels, Official Journal L 076 , 22/03/2003 P. 0010 - 0019

[5] Satterfield CN. Heterogeneous Catalysis in Industrial Practice, McGraw-Hill, New York, 1991;378

[6] Whitehurst DD, Isoda I, Mochida I. Present state of the art and future challenges in the hydrodesulfurization of polyaromatic sulfur compounds. Adv Catal 1998;42:345-71

[7] Speight JG. The Chemistry and Technology of Petroleum, Marcel Dekker: New York, 1991: 209-253

[8] Ma X, Sun L, Song C. A new approach to deep desulfurization of gasoline, diesel fuel and jet fuel by selective adsorption for ultra-clean fuels and for fuel cell applications Catalysis Today, 2002; 77:107-6 
[9] Kobayashi M, Shirai H, Nunokawa M. Estimation of multiple-cycle desulfurization performance for extremely low-concentration sulfur removal with sorbent containing zinc ferrite-silicon dioxide composite powder. Energy Fuels. 2002;16:1378-86

[10] Song C, Ma X. New design approaches to ultra-clean diesel fuels by deep desulfurization and deep dearomatization Appl Catal B 2002; 41:207-38

[11] Yang RT, Hernandez-Maldonado AJ, Yang FH, Desulfurization of transportation fuels with zeolites under ambient conditions. Science 2003; 301:79-81

[12] Velu S, Ma X, Song C. Selective adsorption for removing sulfur from jet fuel over zeolite-based adsorbents. Ind Eng Chem Res 2003;42:5293-304

[13] Haji S, Erkey C. Removal of dibenzothiophene from model diesel by adsorption on carbon aerogels for fuel cell applications. Ind Eng Chem Res 2003;42:6933-37

[14] Song C. An overview of new approaches to deep desulfurization for ultra-clean gasoline, diesel fuel and jet fuel. Catalysis Today 2003;86: 211-63

[15] Ania CO, Bandosz TJ. Importance of structural and chemical heterogeneity of activated carbon surfaces for adsorption of dibenzothiophene. Langmuir $2005 ; 21: 7752-59$

[16] Ania CO, Bandosz TJ. Adsorption of dibenzothiophene from liquid phase by activated carbons. Am Chem Soc 229, Div Fuel Chem 2005;U851-U851 002.

[17] Hines D, Bagreev A, Bandosz TJ. Surface Properties of Porous Carbon Obtained from Polystyrene Sulfonic Acid-Based Organic Salts. Langmuir 2004;20:3388-97

[18] Marczewski AW, Derylo-Marczewska A, Jaroniec M. Correlations of heterogeneity parameters for single-solute and multi-solute adsorption from dilute solutions. J Chem Faraday Trans 1988;84: 2951-57

[19] Olivier JP. Modelling physical adsorption on porous and nonporous solids using density functional theory. J Porous Mater 1995;2:376-7 
[20] Giles C, Mc Ewan T, Nakhwa S, Smith DJ. Studies in Adsorption. Part XI. A system of classification of solutions adsorption isotherms, and its use in diagnosis of adsorption mechanisms and in measurement of specific surface areas of solids. $\mathrm{J}$ Chem Soc 1960:3973

[21] Jiang Z, Liu Y, Sun X, Tian F, Sun F, Liang C, et al. Activated Carbons Chemically Modified by Concentrated H2SO4 for the Adsorption of the Pollutants from Wastewater and the Dibenzothiophene from Fuel Oils. Langmuir 2003;19:731-736

[22] Richardeau D, Joly G, Canaff C, Magnoux P, Guisnet M, Thomas M, et al. Adsorption and reaction over HFAU zeolites of thiophene in liquid hydrocarbon solutions. Appl Catal A 2004;263: 49-61

[23] Hernandez-Maldonado AJ, Yang RT. Desulfurization of commercial liquid fuels by selective adsorption via pi-complexation with $\mathrm{Cu}(\mathrm{I})-\mathrm{Y}$ zeolite. Ind Eng Chem Res 2003;42:3103-10

[24] Mikhail S, Zaki T, Khalil L. Desulfuriation by an economically adsorption technique. App Catal A 2002;227:265-78

[25] Hernandez-Maldonado AJ, Yang RT. Desulfurization of liquid fuels by adsorption via $\pi$ complexation with Cu(I)-Y and Ag-Y zeolites. Ind Eng Chem Res 2003;42:123-29

[26] Derylo-Marczewska A, Marczewski AW. Effect of adsorbate structure on adsorption from solutions. Appl Surf. Sci 2002;196:264-72

[27] Otake Y, Jenkins RG. Characterization of oxygen-containing surface complexes created on microporous carbon by air and nitric acid treatment. Carbon 1993;31:10921

[28] Konno H, Matsumura R, Yamasaki M, Habazaki H. Microstructure of cobalt dispersed carbon sphere prepared from chelate resin. Synth Met 2002;125:167-70 
[29] Morawski AW, Ueda M, Inagaki M, Preparation of transition metal-carbon material from polyacrylonitrile incorporated with inorganic salts. J Mater Sci 1997;32: 789

[30] Inagaki M., Okada Y.; Miura K.; Konno H. Preparation of carbon-coated transition metal particles from mixtures of metal oxide and polyvinylchloride. Carbon 1999; $37: 329-34$

[31] Kaburagi H. Hatori A. Yoshida Y. Nishiyama M. Inagaki M. Carbon films containing transition metal particles of nano and submicron sizes Synthetic Metals. 2001;125: $171-82$

[32] Brunauer S, Deming LS, Deming WE, Teller E. On a theory of the van der Waals adsorption of gases. J Am Chem Soc 1940;62:1723-32

[33] Hafen JA, Mahapatra S, Wilkinson EC, Kaderli S, Young VC, Que L, et al. Reversible cleavage and formation of the dioxygen $\mathrm{O}-\mathrm{O}$ band within a dicopper complex. Science 1996;271:1397-400

[34] Hu Z, Williams RD, Tran D, Spiro TG, Gorun SM. Re-engineering enzyme-model active sites: Reversible binding of dioxygen at ambient conditions by a bioinspired copper complex. J Am Chem Soc 2000;122:3556-7

[35] Kobayashi M, Flytzani-Stephanopoulos M. Reduction and sulfidation kinetics of cerium oxide and Cu-modified cerium oxide. Ind Eng Chem Res 2002;41:3115-23

[36] Nguyen-Thanh D, Bandosz TJ. Activated carbons with metal containing bentonite binders as adsorbents of hydrogen sulphide. Carbon 2005;43:359-67 


\section{CAPTIONS TO THE TABLES}

Table 1.

Fitting parameters to Langmuir-Freundlich equation for DBT adsorption isotherms .

Table 2.

Chemical features of the metal-loaded samples.

Table 3.

Structural features of the carbon studied, evaluated from $\mathrm{N}_{2}$ adsorption isotherms at $77 \mathrm{~K}$ and the DFT method.

Table 5.

Comparison of the amount of sulfur adsorbed on the surface of carbons (from XRF measurements) and the weight loss from TA for the samples exposed to DBT

Table 6.

Limiting capacity for DBT adsorption in the presence of naphthalene (evaluated from the LF equation) 


\section{CAPTIONS TO THE FIGURES}

Figure 1.

Adsorption isotherms of DBT at room temperature on the carbons studied. Solid lines indicate the fit to LF equation.

Figure 2.

DTG curves in nitrogen for the as-received carbons.

Figure 3.

SEM images for cooper and silver modified samples.

Figure 4.

EDX patterns for the metal-loaded carbons.

Figure 5.

Nitrogen adsorption isotherms at 77K.

Figure 6.

Pore size distributions for the carbons before and after DBT adsorption

Figure 7.

Normalized DTG profiles in nitrogen for the carbons after DBT adsorption. 
Table 1. Fitting parameters to Langmuir-Freundlich equation for DBT adsorption isotherms

\begin{tabular}{lccc}
\hline & $\mathrm{q}_{\mathrm{m}}(\mathrm{mg} \mathrm{S} / \mathrm{g})$ & $\mathrm{n}$ & $\mathrm{R}^{2}$ \\
\hline PS- Na & 65 & 0.37 & 0.994 \\
PS-Co & 89 & 0.34 & 0.993 \\
PS-Ag & 77 & 0.40 & 0.998 \\
Ps-Cu & 115 & 0.35 & 0.999 \\
Ps-Cu W & 73 & 0.33 & 0.999 \\
Ps- Cu WW & 46 & 0.32 & 0.990 \\
Bp & 47 & 0.36 & 0.998 \\
\hline
\end{tabular}

Table 2. Chemical features of the metal-loaded samples

\begin{tabular}{lcccc}
\hline & $\mathrm{pH}$ & $\begin{array}{c}\text { Metal } \\
\text { content } \\
(\%)\end{array}$ & $\% \mathrm{O}$ & $\% \mathrm{~S}$ \\
\hline Ps- Na & 3.9 & 3 & 8.1 & 3.3 \\
Ps- Co & 4.8 & 9 & 9.4 & 8.3 \\
Ps- Ag & 4.4 & 7 & 5.4 & 5.2 \\
Ps- Cu & 5.3 & 12.3 & 8.3 & 6.9 \\
Ps-Cu W & 4.5 & 8.1 & 7.2 & 4.6 \\
Ps-Cu WW & 4.1 & 1.2 & 6.7 & 3.2 \\
\hline
\end{tabular}

Table 3. Structural features of the carbon studied, evaluated from $\mathrm{N}_{2}$ adsorption isotherms at $77 \mathrm{~K}$ and the DFT method

\begin{tabular}{lccccc}
\cline { 3 - 5 } & & \multicolumn{4}{c}{ DFT method } \\
\hline & $\begin{array}{c}\mathrm{S}_{\mathrm{BET}} \\
\left(\mathrm{m}^{2} \mathrm{~g}^{-1}\right)\end{array}$ & $\begin{array}{c}\mathrm{V}_{\mathrm{T}} \\
\left(\mathrm{cm}^{3} \mathrm{~g}^{-1}\right) \\
\left(\mathrm{p} / \mathrm{po}^{-1} 0.99\right)\end{array}$ & $\begin{array}{c}\mathrm{V}_{\text {narrow }} \\
\text { micropores } \\
\left(\mathrm{cm}^{3} \mathrm{~g}^{-1}\right)\end{array}$ & $\begin{array}{r}\mathrm{V}_{\text {medium- }} \\
\text { micropores } \\
\left(\mathrm{cm}^{3} \mathrm{~g}^{-1}\right)\end{array}$ & $\begin{array}{c}\mathrm{V}_{\text {mesopores }} \\
\left(\mathrm{cm}^{3} \mathrm{~g}^{-1}\right)\end{array}$ \\
\hline PS-Na & 1737 & 0.903 & 0.118 & 0.359 & 0.287 \\
PS-Co & 1096 & 0.971 & 0.069 & 0.195 & 0.172 \\
PS-Ag & 461 & 0.284 & 0.052 & 0.086 & 0.084 \\
PS-Cu & 566 & 0.342 & 0.065 & 0.104 & 0.095 \\
PS-Cu W & 748 & 0.439 & 0.068 & 0.141 & 0.128 \\
Ps-Cu WW & 774 & 0.456 & 0.099 & 0.159 & 0.145 \\
\hline
\end{tabular}


Table 4. Comparison of copper content on the carbon surface and the amount of DBT adsorbed

\begin{tabular}{lccc}
\hline & $\begin{array}{c}\text { Metal } \\
\text { content } \\
{[\mathrm{mmol} / \mathrm{g}]}\end{array}$ & $\begin{array}{c}\text { DBT } \\
\text { adsorbed } \\
{[\mathrm{mmol} / \mathrm{g}]}\end{array}$ & $\begin{array}{c}\text { ratio } \\
\text { metal/DBT } \\
\text { adsorbed } \\
{[\mathrm{mol} / \mathrm{mol}]}\end{array}$ \\
\hline PS-Cu & 1.94 & 3.6 & 0.54 \\
PS-Cu W & 1.27 & 2.3 & 0.55 \\
PS-Cu WW & 0.19 & 1.4 & 0.14 \\
\hline
\end{tabular}

Table 5. Comparison of the amount of sulfur adsorbed on the surface of carbons (from XRF measurements) and the weight loss from TA for the samples exposed to DBT

\begin{tabular}{lcc}
\hline & $\begin{array}{c}\% \\
\text { adsorbed }\end{array}$ & $\begin{array}{c}\text { Mass loss } \\
\text { TA (\%) }\end{array}$ \\
\hline Ps- Na & 39 & 9.3 \\
Ps- Ag & 45 & 5.5 \\
Ps- Co & 55 & 8.3 \\
Ps- Cu & 67 & 6.7 \\
PS-Cu W & 43 & 7.0 \\
PS-Cu WW & 27 & 10.3 \\
\hline
\end{tabular}

Table 6. Limiting capacity for DBT adsorption in the presence of naphthalene (evaluated from the LF equation)

\begin{tabular}{ccccc}
\hline & $\begin{array}{c}\text { DBT } \\
\text { adsorbed } \\
\text { (mg S/g) }\end{array}$ & $\begin{array}{c}\text { \% loss } \\
\text { DBT adsorption } \\
\text { capacity }\end{array}$ & $\begin{array}{c}\text { Naph. } \\
\text { Adsorbed } \\
\text { (\% wt) }\end{array}$ & $\begin{array}{c}\text { \% loss } \\
\text { Naph. adsorption } \\
\text { capacity }\end{array}$ \\
\hline Ps-Cu & 90 & 22 & 0.05 & 10 \\
Ps-Cu W & 56 & 23 & 0.05 & 9 \\
Ps- Cu WW & 26 & 44 & 0.07 & 6 \\
\hline
\end{tabular}




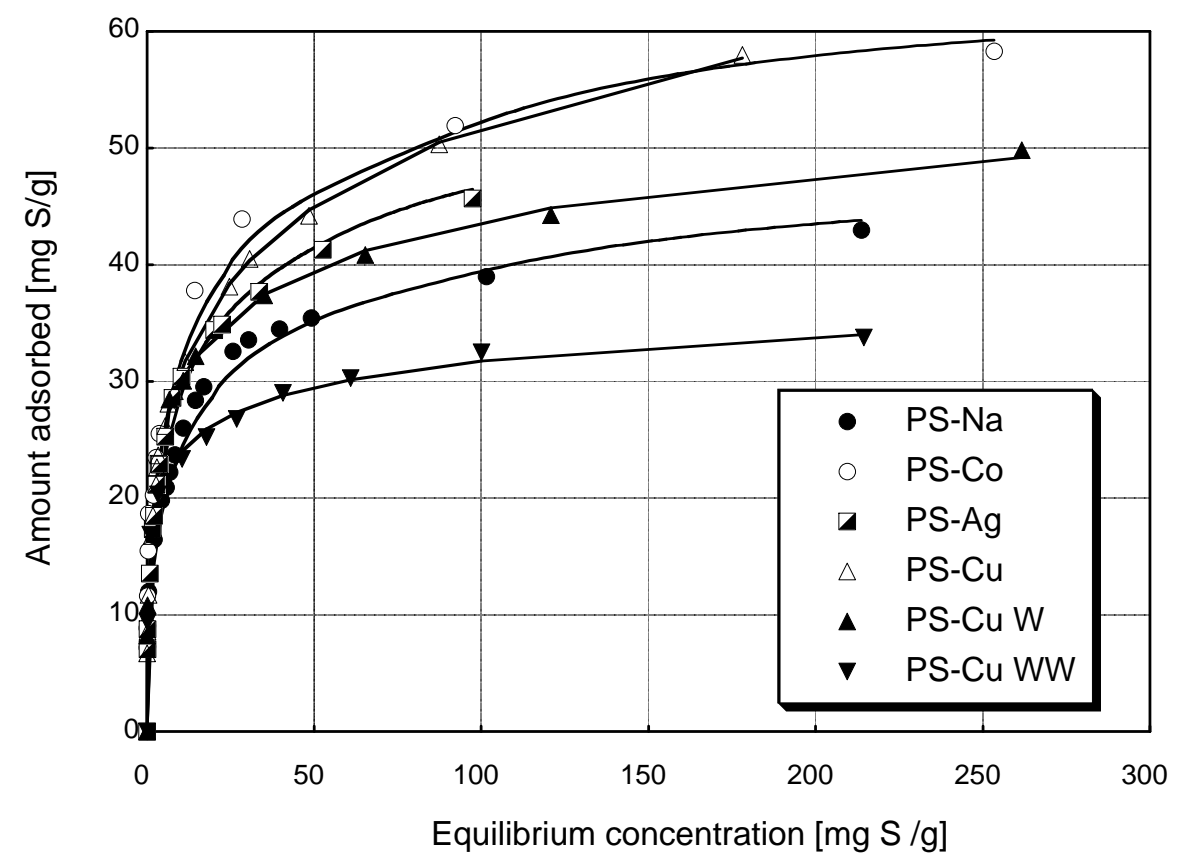

Figure 1. Adsorption isotherms of DBT at room temperature on the carbons studied. Solid lines indicate the fit to LF equation. 

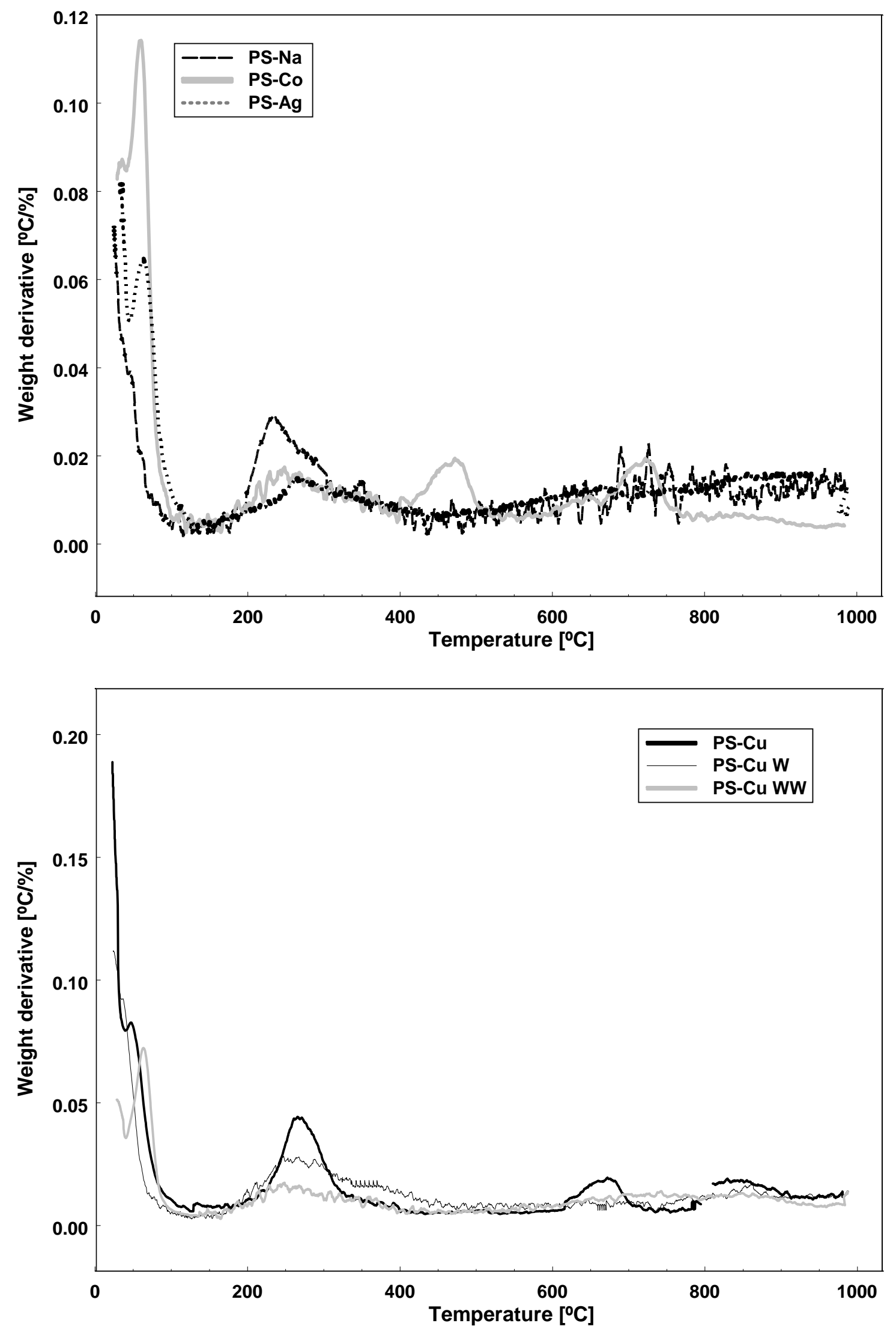

Figure 2. DTG curves in nitrogen for the as-received carbons. 

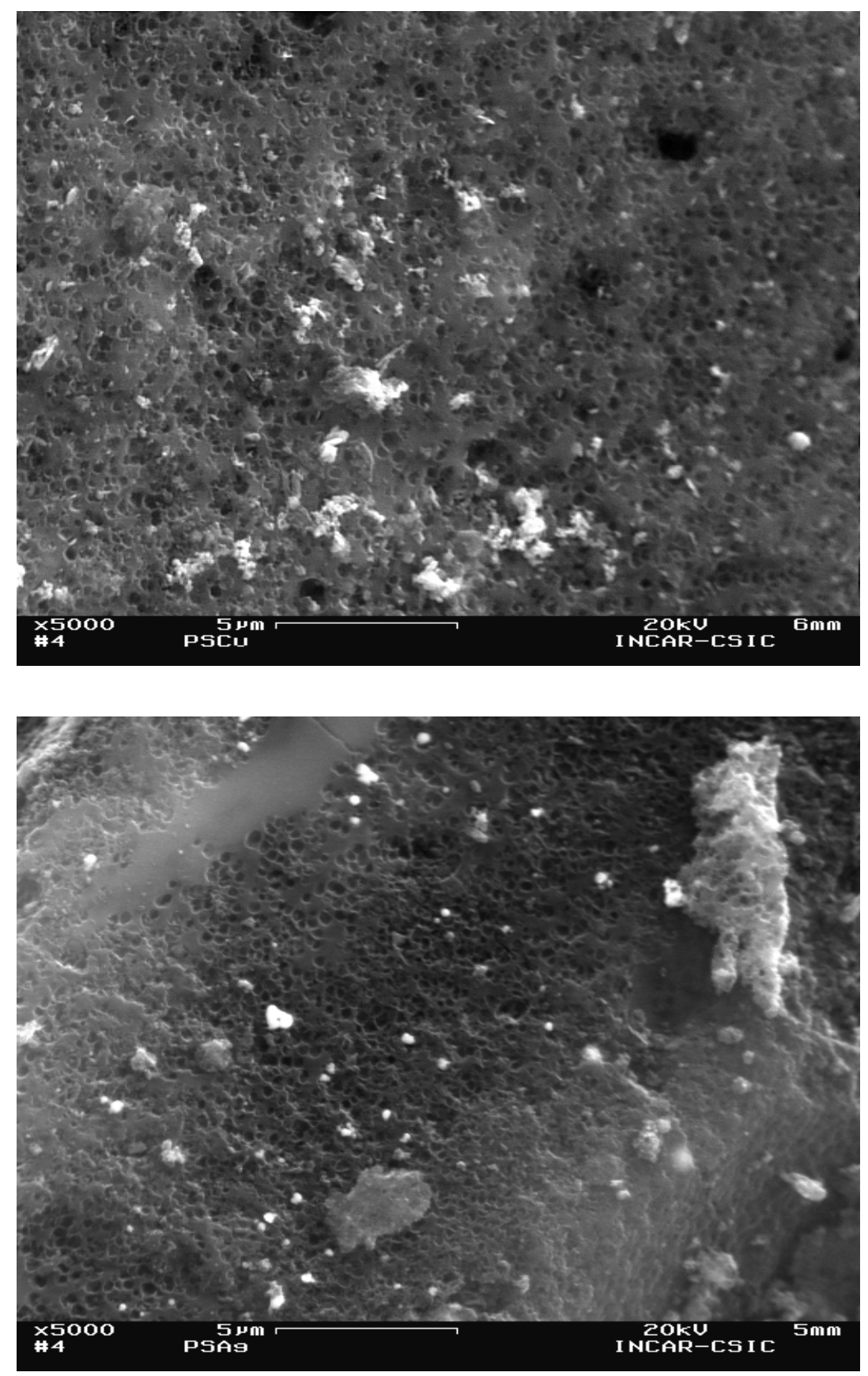

Figure 3. SEM images for cooper and silver modified samples. 
Figure 4. EDX patterns for the metal-loaded carbons.

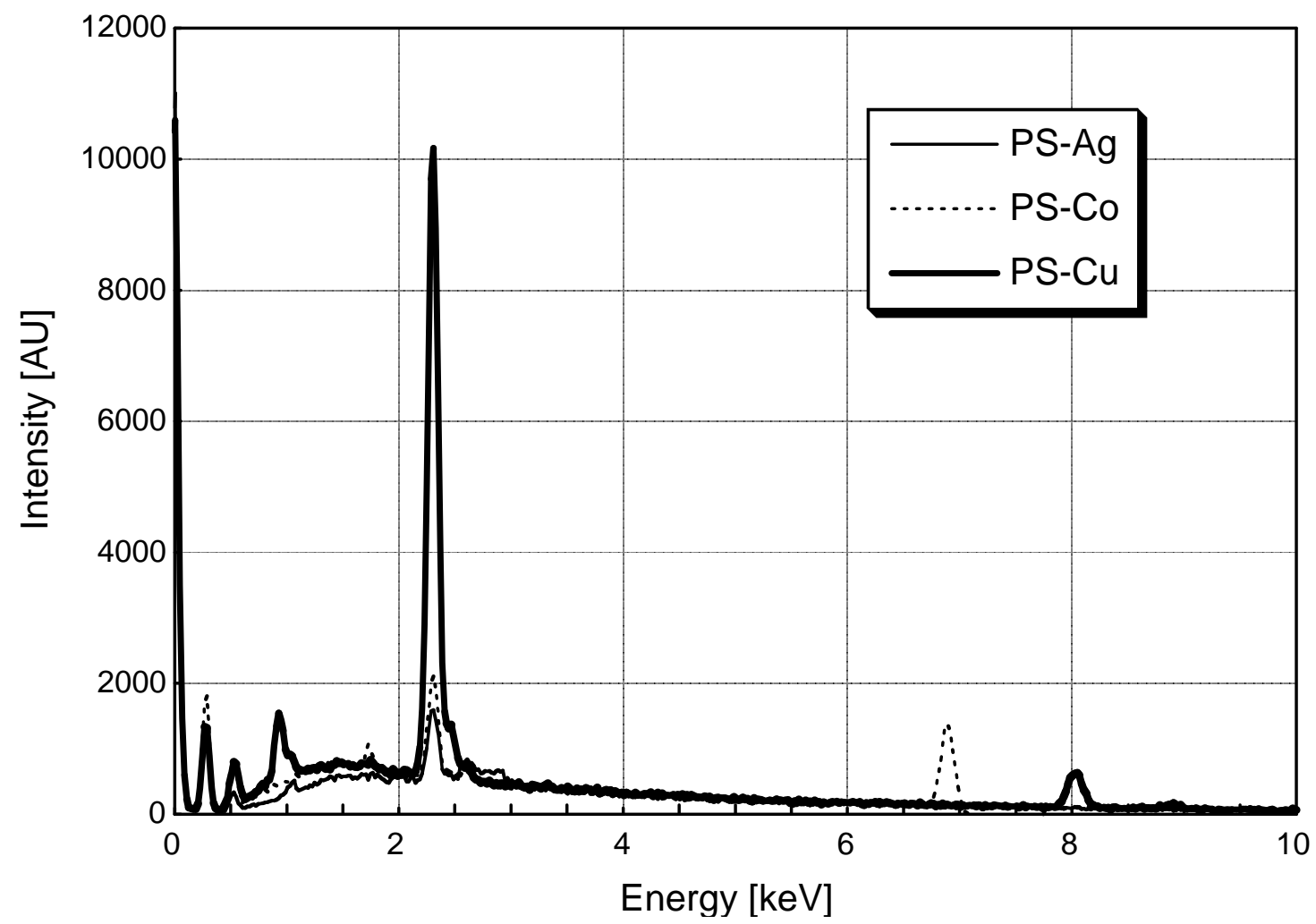


Figure 5. Nitrogen adsorption isotherms at 77K.

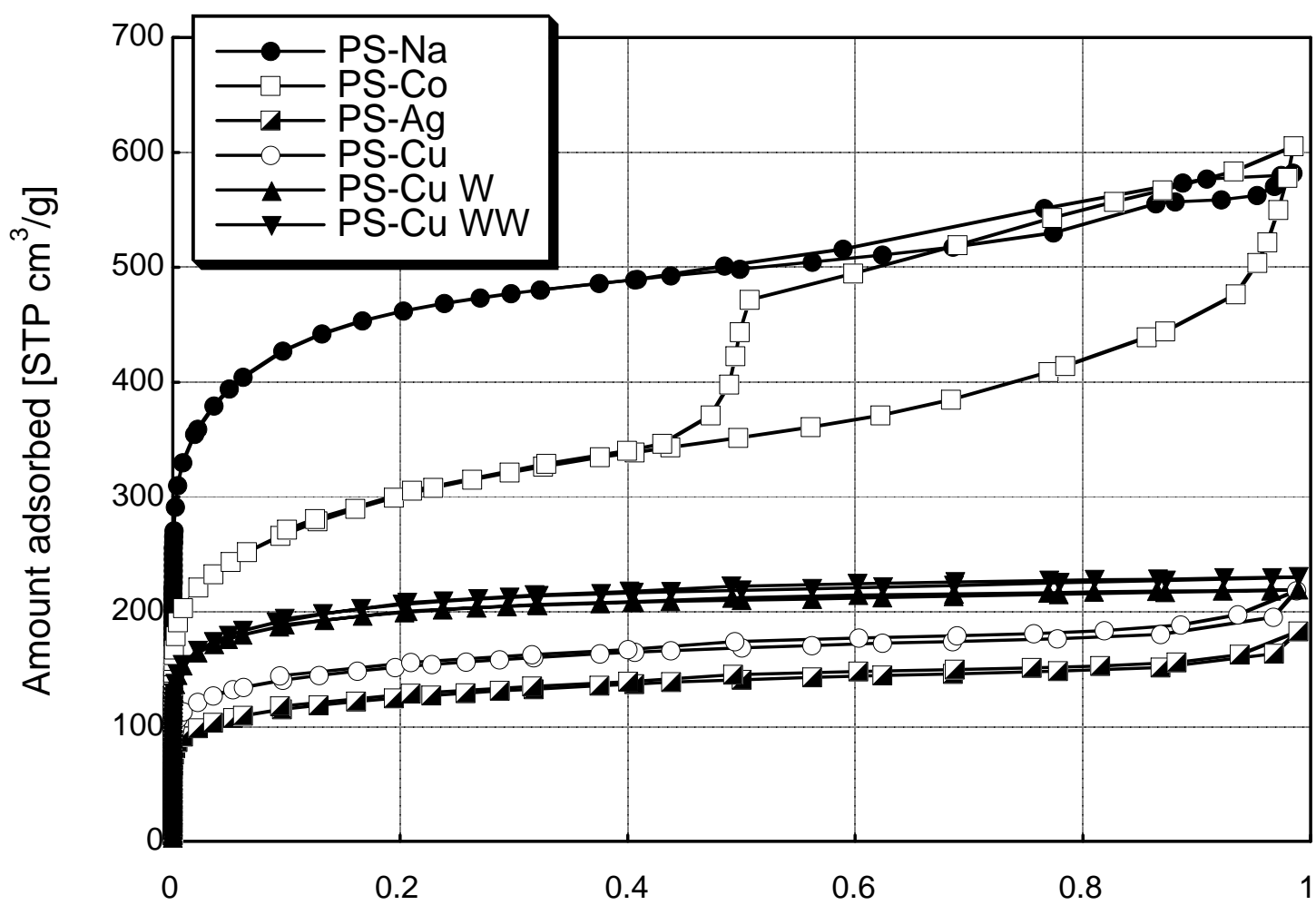

Relative pressure 
Figure 6. Pore size distributions for the carbons before and after DBT adsorption.
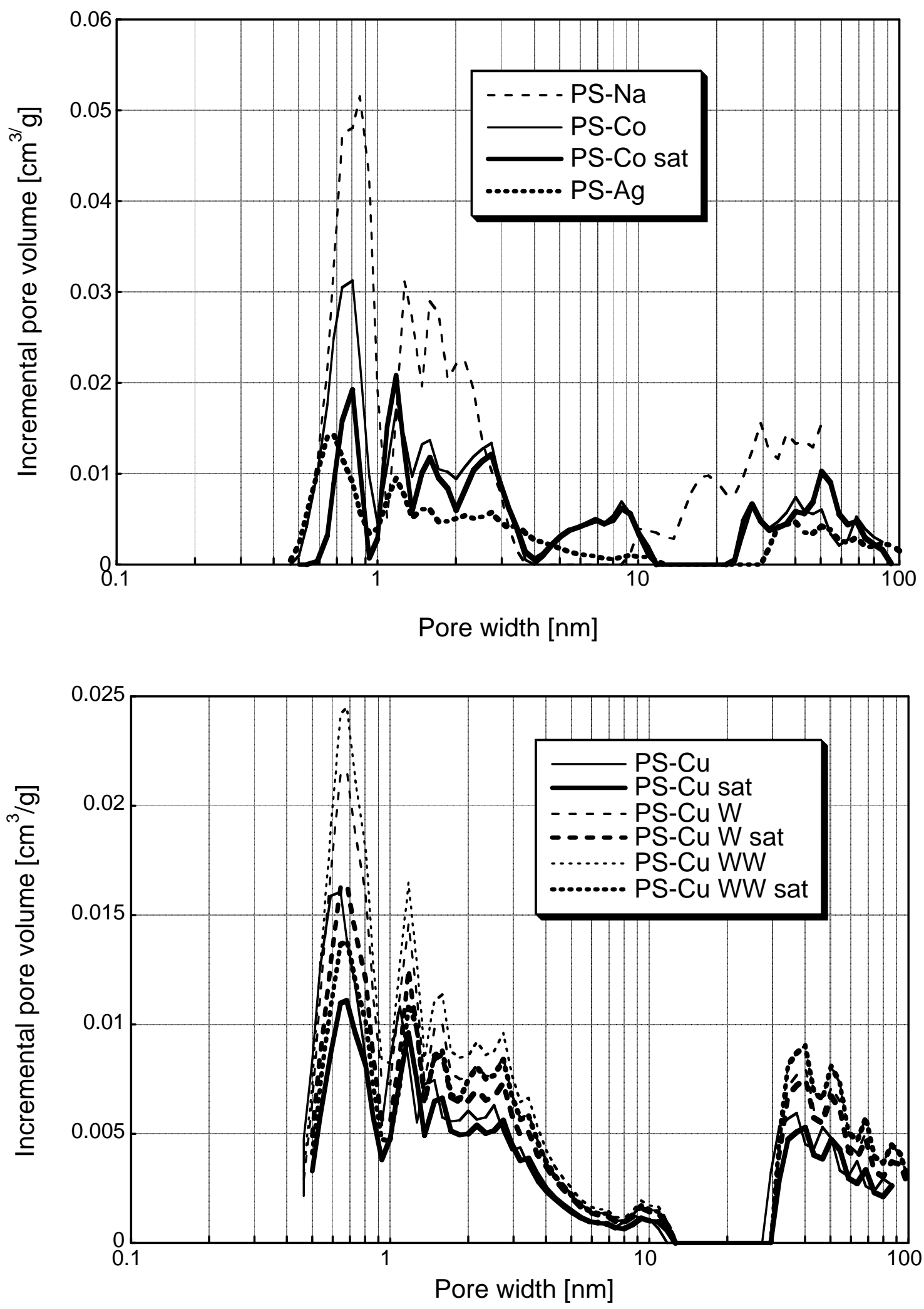


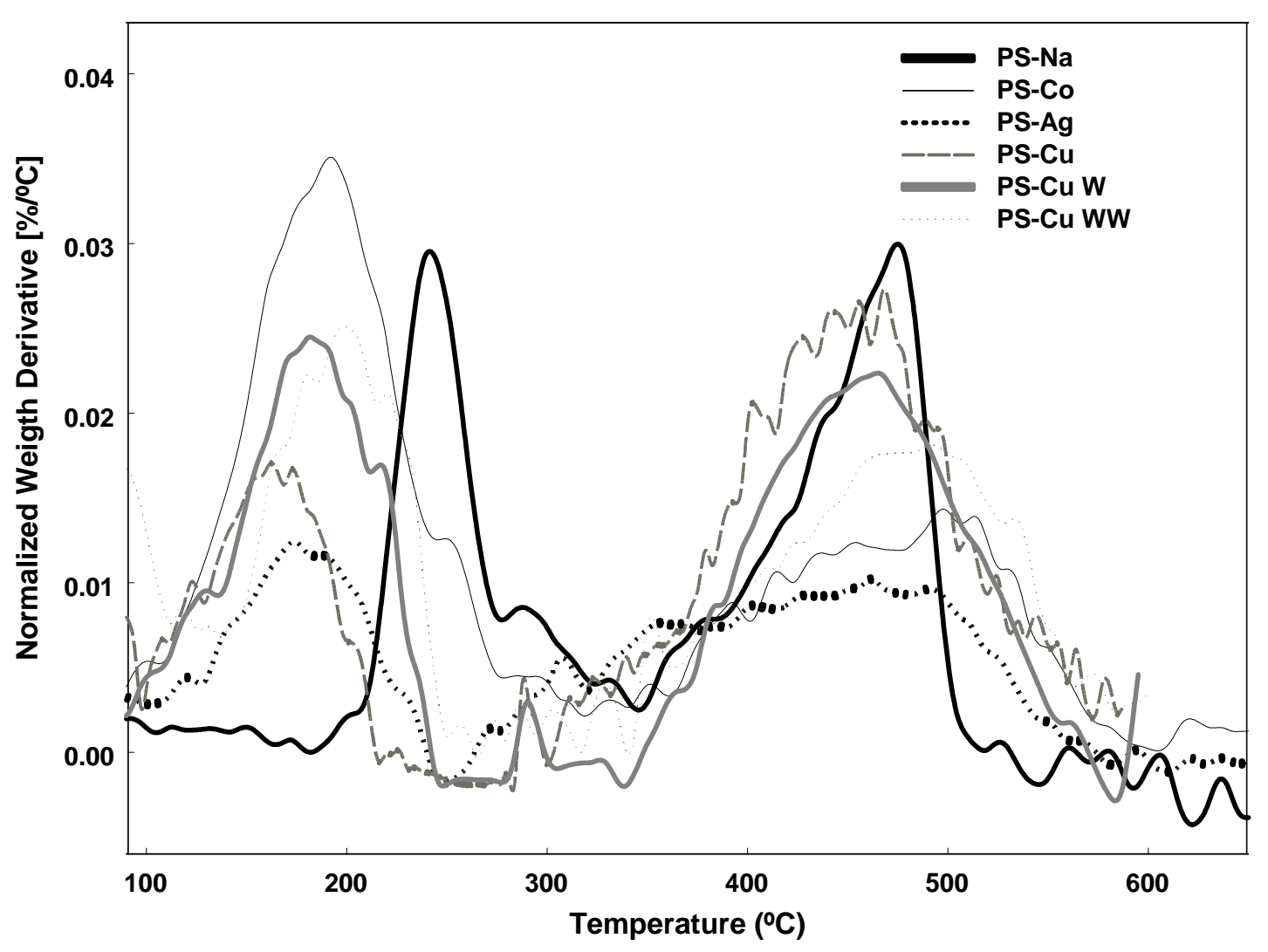

Figure 7. Normalized DTG profiles in nitrogen for the carbons after DBT adsorption. 